\title{
Role of sulfite additives in wine induced asthma: single dose and cumulative dose studies
}

\author{
H Vally, P J Thompson
}

\begin{abstract}
Background-Wine appears to be a significant trigger for asthma. Although sulfite additives have been implicated as a major cause of wine induced asthma, direct evidence is limited. Two studies were undertaken to assess sulfite reactivity in wine sensitive asthmatics. The first study assessed sensitivity to sulfites in wine using a single dose sulfited wine challenge protocol followed by a double blind, placebo controlled challenge. In the second study a cumulative dose sulfited wine challenge protocol was employed to establish if wine sensitive asthmatics as a group have an increased sensitivity to sulfites.

Methods-In study 1, 24 asthmatic patients with a strong history of wine induced asthma were screened. Subjects showing positive responses to single blind high sulfite $(300 \mathrm{ppm})$ wine challenge were rechallenged on separate days in a double blind, placebo controlled fashion with wines of varying sulfite levels to characterise their responses to these drinks. In study 2, wine sensitive asthmatic patients $(n=12)$ and control asthmatics $(n=6)$ were challenged cumulatively with wine containing increasing concentrations of sulfite in order to characterise further their sensitivity to sulfites in wine.
\end{abstract}

Results-Four of the 24 self-reporting wine sensitive asthmatic patients were found to respond to sulfite additives in wine when challenged in a single dose fashion (study 1). In the double blind dose-response study all four had a significant fall in forced expiratory volume in one second $\left(\mathrm{FEV}_{1}\right)$ (>15\% from baseline) following exposure to wine containing 300 ppm sulfite, but did not respond to wines containing 20, 75 or 150 ppm sulfite. Responses were maximal at 5 minutes (mean (SD) maximal decline in $\mathrm{FEV}_{1} 28.7$ (13)\%) and took 15-60 minutes to return to baseline levels. In the cumulative doseresponse study (study 2) no significant difference was observed in any of the lung function parameters measured $\left(\mathrm{FEV}_{1}\right.$, peak expiratory flow (PEF), mid phase forced expiratory flow $\left(\mathrm{FEF}_{25-75}\right)$ ) between wine sensitive and normal asthmatic subjects.

Conclusions-Only a small number of wine sensitive asthmatic patients responded to a single dose challenge with sulfited wine under laboratory conditions.
This may suggest that the role of sulfites and/or wine in triggering asthmatic responses has been overestimated. Alternatively, cofactors or other components in wine may play an important role in wine induced asthma. Cumulative sulfite dose challenges did not detect an increased sensitivity to sulfite in wine sensitive asthmatics and an alternative approach to identifying sulfite/wine sensitive asthma may be required.

(Thorax 2001;56:763-769)

Keywords: asthma; wine; sulfite additives

Wine appears to be a significant trigger for asthma. A recent community survey in Australia suggests that approximately $30 \%$ of asthmatic patients believe that wine is associated with worsening asthma symptoms. ${ }^{1}$ Despite this, very little is known about wine induced asthma and its aetiology. Although the sulfite additives found in wine have been implicated as an important factor, ${ }^{2}$ few studies have assessed this. ${ }^{3-5}$ The degree to which sulfites contribute to wine induced asthma and the characteristics of these responses thus remain poorly described.

In previous studies from our laboratory a small group of asthmatic patients were observed to be exquisitely sensitive to sulfite additives and reacted consistently to challenge with sulfite-containing wine. ${ }^{3}$ In contrast, there appeared to be a larger group of patients who provided very convincing histories of reactivity to the sulfites in wine, but whose sensitivity was less marked and did not respond to challenge with sulfited wine. This second group of patients has proved difficult to study, raising some doubt as to the true extent of sulfite/wine induced asthma. We report two different approaches that aimed to describe and further understand the role of sulfites in wine induced asthma. Firstly, individuals found to be highly sensitive to sulfites in wine were challenged with wines of varying sulfite levels to establish the dose-response characteristics of their sulfite/wine sensitivity. In the second approach, a cumulative challenge protocol was used to determine the sensitivity of asthmatic subjects to sulfites in wine compared with asthma patients tolerant to wine.

\section{Methods}

SUBJECTS

Wine sensitive asthmatic patients with a history of repeated episodes of worsening asthma within 30 minutes of wine consumption were recruited. Subjects with liver disease or other 
serious medical conditions and those who were pregnant were excluded, as were those taking medications known to interact with alcohol. Patients whose adverse reactions to wine had previously resulted in admission to hospital and those with an obvious impairment in alcohol metabolism were also excluded. Subjects were only entered into the study if their asthma was stable and mild. Selection criteria included having used bronchodilators on $<3$ occasions per day, waking with asthma on $<5$ occasions in the previous month, and not taking oral corticosteroids to control asthma symptoms in the previous 2 months. All individuals entering the study were required to have an $\mathrm{FEV}_{1}$ of $>70 \%$ predicted or $>1.51$. Medication use was restricted before each challenge visit: short acting $\beta_{2}$ agonists were restricted for 8 hours, cromolyn/nedocromil, inhaled steroids, and anticholinergics for 12 hours, long acting $\beta_{2}$ agonists and short acting antihistamines for 24 hours, and theophylline for 3 days before challenge.

This study was approved by the Committee for Human Rights of the University of Western Australia and all subjects provided informed consent prior to participating.

CHALLENGE WINE PREPARATION

Commercially available sulfite free white wine (BRL Hardy, South Australia) was used in this study and the sulfite level of this wine was determined as described by Rankine. ${ }^{6}$ The sulfite level in sulfite free white wine ranged from 10 to $20 \mathrm{ppm}$. To prepare wines with the required sulfite concentration, sulfite free white wine was spiked with known quantities of sodium metabisulfite $\left(\mathrm{Na}_{2} \mathrm{~S}_{2} \mathrm{O}_{5}\right)$ and the sulfite levels confirmed. Challenge wines were freshly prepared each day and preliminary studies confirmed that there was no loss of sulfite and no appreciable change in the proportion of free to bound sulfite over the period of each study day.

SULFITED WINE DOSE-RESPONSE STUDY (STUDY 1) Study design

Twenty four asthmatic subjects (20 women, mean (SD) age 38.0 (10.5) years, range 24-60) were screened for this study. Clinical details of asthma and wine sensitivities were recorded for all patients. Subjects were initially challenged with high sulfite wine $(300 \mathrm{ppm})$ to establish if they were sensitive to sulfite additives in wine. Those responding to this single blind high sulfite wine challenge were then challenged, on separate days in a double blind, placebo controlled fashion, with wines containing $10-20 \mathrm{ppm}, 75 \mathrm{ppm}, 150 \mathrm{ppm}$ or $300 \mathrm{ppm}$ sulfite.

\section{Single blind wine challenge}

Baseline spirometric parameters (Vitalograph, UK) were determined for all subjects. Subjects then consumed $150 \mathrm{ml}$ high sulfite wine over a period of 5 minutes and spirometric values were monitored for 1 hour following the challenge. A fall in $\mathrm{FEV}_{1}$ of $>15 \%$ was considered to be a positive response. To confirm that this was due to the sulfite additives patients were challenged on a separate day with sulfite free wine. Patients demonstrating a positive response to the high sulfite wine challenge but not to the challenge with sulfite free wine were recruited into the double blind phase of the study.

Double blind (sulfite) dose-response challenge

Double blind challenges were carried out on separate days with sulfite free wine (10$20 \mathrm{ppm}$ sulfite) and wines containing low (75 ppm), moderate (150 ppm), and high sulfite $(300 \mathrm{ppm})$ concentrations. The order of challenges was determined using a latin square design. Baseline $\mathrm{FEV}_{1}$ was assessed at the beginning of each study day and was required to be within $10 \%$ of the baseline $\mathrm{FEV}_{1}$ at entry into the study. Challenges were conducted at least 48 hours apart (where possible, not more than 8 days apart) and at the same time of day ( \pm 1 hour). After equilibrating for 5 minutes at room temperature, $150 \mathrm{ml}$ of chilled white wine $\left(4^{\circ} \mathrm{C}\right)$ was consumed over a period of 5 minutes. Spirometric measurements were started immediately after wine consumption (5 minutes) and were repeated at 15, 30, and 60 minutes after the challenge. The best of three measurements was recorded for each time point. A fall in $\mathrm{FEV}_{1}$ of $>15 \%$ from prechallenge values was predetermined as a positive response to challenge, while a fall in $\mathrm{FEV}_{1}$ of $>25 \%$ resulted in the mandatory withdrawal of the subject from the study day and treatment with an appropriate bronchodilator. The atopic status of subjects participating in this study was determined by skin prick testing with standard allergens, as well as histamine and brewers' yeast.

\section{Subjective measurements of responses to wine} challenges

Subjects were asked to indicate the intensity of their asthma symptoms on a visual analogue scale (VAS) both before and after each wine challenge. The VAS consisted of a line $100 \mathrm{~mm}$ in length, anchored on the left with no symptoms and on the right with severe symptoms. All responses were recorded as scores between 0 and 100, based on the distance in $\mathrm{mm}$ from the left of this line.

SULFITE CUMULATIVE DOSE RESPONSE CHALLENGE STUDY (STUDY 2)

Study design

Eighteen asthmatic subjects of mean (SD) age 35.4 (11.2) years (range 20-56) were recruited into this study. Clinical details of wine sensitivity were recorded and atopic status was determined by standard allergen skin prick testing. Subjects were required to make two visits to the asthma clinic for this study. On the first visit it was confirmed that the subject could tolerate sulfite free white wine without a significant decline in lung function. On the second visit subjects were required sequentially to consume aliquots of white wine which had been spiked with increasing concentrations of sulfite in order to assess their sensitivity to the additive. 
Table 1 Patient details and history (study 1)

\begin{tabular}{|c|c|c|c|c|c|c|c|c|}
\hline Patient no. & Sex & Age (years) & $\begin{array}{l}\text { Asthma } \\
\text { medications }^{1}\end{array}$ & $\begin{array}{l}\text { History of wine } \\
\text { sensitivity }^{2}\end{array}$ & $\begin{array}{l}\text { Sulfite sensitive } \\
\text { history }^{3}\end{array}$ & $\begin{array}{l}\text { Baseline } \\
F E V_{1}(l)\end{array}$ & $\begin{array}{l}\text { Baseline FEV } \\
\text { (\% pred) }\end{array}$ & $\begin{array}{l}\text { Positive high } \\
\text { sulfite challenge }\end{array}$ \\
\hline 1 & $\mathrm{~F}$ & 30 & ba & champ, wh & $\mathrm{Y}$ & 2.58 & 76.6 & $\mathrm{~N}$ \\
\hline 2 & $\mathrm{~F}$ & 26 & $\mathrm{ba}, \mathrm{bc}$ & red, wh,ch & $\mathrm{Y}$ & 3.53 & 99.4 & $\mathrm{Y}$ \\
\hline 3 & $\mathrm{~F}$ & 52 & ba & red, wh, champ, ch & $\mathrm{Y}$ & 2.13 & 74.5 & $\mathrm{~N}$ \\
\hline 4 & $\mathrm{~F}$ & 31 & ba & red, wh, champ & $\mathrm{Y}$ & 3.18 & 97.8 & $\mathrm{Y}$ \\
\hline 5 & $\mathrm{~F}$ & 28 & ba, bu & red, wh & $\mathrm{N}$ & 3.22 & 97.2 & $\mathrm{~N}$ \\
\hline 6 & $M$ & 30 & ba & wh, ch & $\mathrm{N}$ & 4.81 & 106.7 & $\mathrm{~N}$ \\
\hline 7 & $\mathrm{~F}$ & 28 & ba & red, wh, champ & $\mathrm{N}$ & 3.26 & 105.2 & $\mathrm{~N}$ \\
\hline 8 & $M$ & 28 & ba & red & $\mathrm{N}$ & 3.34 & 80.1 & $\mathrm{~N}$ \\
\hline 9 & $\mathrm{~F}$ & 30 & ba & red, wh, champ, ch & $\mathrm{N}$ & 3.81 & 108.2 & $\mathrm{~N}$ \\
\hline 10 & $\mathrm{~F}$ & 53 & $\mathrm{ba}, \mathrm{bc}$ & red, wh & $\mathrm{N}$ & 2.56 & 944.5 & $\mathrm{~N}^{4}$ \\
\hline 11 & $\mathrm{M}$ & 43 & $\mathrm{ba}, \mathrm{sm}, \mathrm{bc}$ & red, wh & $\mathrm{N}$ & 3.65 & 95.5 & $\mathrm{~N}$ \\
\hline 12 & $\mathrm{~F}$ & 27 & ba, bu & red, wh, champ & $\mathrm{Y}$ & 1.85 & 61.6 & $\mathrm{Y}$ \\
\hline 13 & $\mathrm{~F}$ & 44 & $\mathrm{ba}, \mathrm{bc}, \mathrm{sm}$ & wh, champ & $\mathrm{Y}$ & 2.24 & 80.0 & $\mathrm{~N}$ \\
\hline 14 & $\mathrm{~F}$ & 54 & ba & red, wh, champ, ch & $\mathrm{Y}$ & 2.51 & 97.7 & $\mathrm{~N}$ \\
\hline 15 & $\mathrm{~F}$ & 45 & $\mathrm{ba}, \mathrm{bc}$ & red, wh, champ & $\mathrm{Y}$ & 2.12 & 84.8 & $\mathrm{~N}$ \\
\hline 16 & $M$ & 35 & ba, bu & red, wh & $\mathrm{N}$ & 3.48 & 84.9 & $\mathrm{~N}$ \\
\hline 17 & $\mathrm{~F}$ & 46 & ba, bu & red, wh, ch & $\mathrm{N}$ & 1.90 & 86.4 & $\mathrm{~N}$ \\
\hline 18 & $\mathrm{~F}$ & 24 & ba & red, wh, ch & $\mathrm{Y}$ & 2.73 & 70.0 & $\mathrm{Y}$ \\
\hline 19 & $\mathrm{~F}$ & 48 & $\mathrm{ba}, \mathrm{bc}$ & wh & $\mathrm{N}$ & 2.10 & 84.0 & $\mathrm{~N}$ \\
\hline 20 & $\mathrm{~F}$ & 60 & ba, bc, th & wh, ch & $\mathrm{N}$ & 1.63 & 65.2 & $\mathrm{~N}^{4}$ \\
\hline 21 & $\mathrm{~F}$ & 38 & ba & wh, champ, ch & $\mathrm{N}$ & 2.86 & 81.7 & $\mathrm{~N}$ \\
\hline 22 & $\mathrm{~F}$ & 30 & $\mathrm{ba}, \mathrm{bc}$ & wh & $\mathrm{N}$ & 2.56 & 80.0 & $\mathrm{~N}$ \\
\hline 23 & $\mathrm{~F}$ & 41 & ba & wh, ch & $\mathrm{N}$ & 1.91 & 70.7 & $\mathrm{~N}$ \\
\hline 24 & $\mathrm{~F}$ & 40 & ba, th & wh, ch & $\mathrm{N}$ & 1.44 & 60.0 & $\mathrm{ND}^{5}$ \\
\hline
\end{tabular}

$\mathrm{FEV}_{1}=$ forced expiratory volume in one second; \% pred = percentage of predicted value; $\mathrm{ND}=$ not studied.

${ }^{1} \mathrm{ba}=\beta_{2}$ adrenoceptor agonists; $\mathrm{bc}=$ beclomethasone; $\mathrm{bu}=$ budesonide; $\mathrm{cr}=$ cromoglycate; $\mathrm{sm}=$ salmeterol; ip = ipratropium bromide; th =theophylline.

${ }^{2}$ red $=$ red wine; wh $=$ white wine champ $=$ champagne ch $=$ cheap wine.

${ }^{3}$ Patients presenting with a history suggestive of a sensitivity to sulfite additives.

${ }^{4}$ Patients exhibiting a positive response to both high sulfite and sulfite-free wine challenge.

${ }^{5}$ Patient not studied, minimum lung function criteria not met.

Asthmatic subjects in this study were divided into two groups based on their prior history of wine sensitivities: (1) control group $(n=6)$ of asthmatic subjects who had consumed wines previously but had never experienced any asthma symptoms following their consumption, and (2) a wine sensitive group of asthmatic subjects with a sulfite sensitive history $(n=12)$ who reported a history of repeated episodes of worsening asthma symptoms within 30 minutes of wine consumption. These subjects were also required to satisfy criteria that suggested a role for sulfite additives in their responses. These were (a) that white wines were generally more of a problem for them than red wines, or (b) that cheaper wines were more of a problem than expensive wines, or (c) that, in addition to their sensitivity to wines, a selection of sulfite containing foods (notably, preserved fruits and vegetables) were also associated with triggering asthmatic responses.

Single blind sulfite free wine challenge (visit 1)

After determining baseline lung function, subjects ingested $150 \mathrm{ml}$ of sulfite free white wine over a 5 minute period. Lung function was assessed immediately after drinking the wine ( 5 minutes) and at 15 and 30 minutes after the challenge. The best of three measurements was recorded for each time point. A fall in $\mathrm{FEV}_{1}$ of $>15 \%$ of prechallenge $\mathrm{FEV}_{1}$ was considered to be a positive response to the challenge. Patients exhibiting a positive response to challenge with sulfite free wine did not proceed to the cumulative dose-response challenge study day.

Sulfite cumulative dose-response challenge (visit 2) Baseline $\mathrm{FEV}_{1}$ was assessed at the beginning of the study day and was required to be within $10 \%$ of the baseline $\mathrm{FEV}_{1}$ at entry into the study. This second challenge was conducted at least 48 hours after the single blind challenge with sulfite free wine and, where possible, not more than 8 days after this challenge. The challenge protocol involved the equilibration of $50 \mathrm{ml}$ of chilled $\left(4^{\circ} \mathrm{C}\right)$ white wine at room temperature for 3 minutes, then the consumption of this white wine over a period of 5 minutes. Lung function was measured immediately after wine consumption ( 5 minutes) and 15 minutes after the challenge. If no significant decline in lung function was observed (fall in $\mathrm{FEV}_{1}$ of $>15 \%$ ), subjects were challenged with the next wine drink in identical fashion. This cycle was completed for each of the sulfited wine challenge drinks (150 ppm, $300 \mathrm{ppm}$, $450 \mathrm{ppm}$, and $750 \mathrm{ppm}$ ).

\section{DATA ANALYSIS}

The INSTAT statistics program (Graphpad Software, San Diego, CA, USA) was used for all statistical analyses. Differences between groups were assessed by ANOVA or Student's $t$ test as appropriate, with a $\mathrm{p}$ value $<0.05$ indicating a significant difference.

\section{Results}

SULFITE DOSE-RESPONSE STUDY (STUDY 1) Subjects

The characteristics of the subjects screened for this study are summarised in table 1 . Of the 24 subjects assessed, only four exhibited a positive response to high sulfite wine and a negative response to sulfite free wine challenge and were thus recruited into the double blind phase of the study (subjects $2,4,12$, and 18). Two subjects (subjects 10 and 20) exhibited positive responses to high sulfite wine and sulfite free wine, and one subject (subject 24) was not challenged after initial screening after failing to meet minimum lung function criteria for participation. 
Table 2 Mean maximum fall in $\mathrm{FEV}_{1}, \mathrm{FEF}_{25-75}$, and $\mathrm{PEF}$ in four subjects following challenge with wine of varying sulfite concentrations (study 1)

\begin{tabular}{lllll}
\hline & Sulfite free $(\sim 20 \mathrm{ppm})$ & Low sulfite $(75 \mathrm{ppm})$ & $\begin{array}{l}\text { Moderate sulfite } \\
(150 \text { ppm })\end{array}$ & High sulphite (300 ppm) \\
\hline $\mathrm{FEV}_{1}(\%)$ & $-4.4(-13.2$ to 4.4$)$ & $-6.5(-17.9$ to 4.9$)$ & $-1.4(-14.2$ to 11.3$)$ & $-28.7(-49.7 \text { to }-7.7)^{\star}$ \\
$\mathrm{FEF}_{25-75}(\%)$ & $-10.5(-34.8$ to 13.8$)$ & $-11.4(-38.1$ to 15.3$)$ & $-1.1(-34.3$ to 32.2$)$ & $-48,4(-81.9 \text { to }-14.9)^{\star \star}$ \\
$\mathrm{PEF}^{(\%)}$ & $-7.2(-17.2$ to 2.8$)$ & $-9.4(-18.5$ to -0.2$)$ & $-3.2(-21.9$ to 15.6$)$ & $-28.3(-46.7 \text { to }-10.0)^{\star}$ \\
\hline
\end{tabular}

$\mathrm{FEV}_{1}=$ forced expiratory volume in one second; $\mathrm{FEF}_{25-75}=$ mean expired flow over the middle half of the FVC manoeuvre; $\mathrm{PEF}=$ peak expiratory flow.

${ }^{1}$ Means are expressed as a percentage of baseline values $(95 \% \mathrm{CI})$.

${ }^{\star} \mathrm{p}<0.05,{ }^{\star \star} \mathrm{p}<0.01$ compared with sulfite free wine.

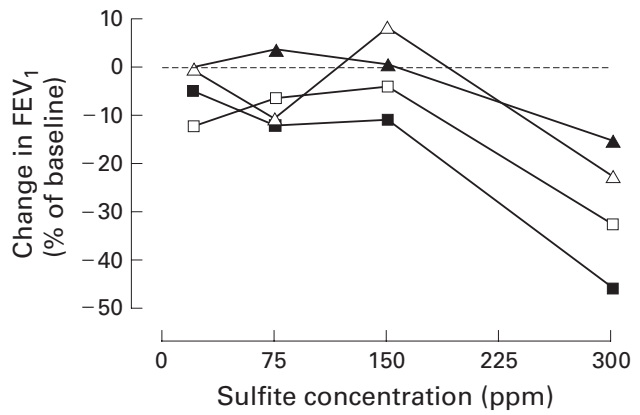

Figure 1 Dose-response curve of sensitivities to sulfite additives in wine in subjects 2 ( $(\square), 4(\mathbf{(}), 12(\triangle)$, and 18
$(\mathbf{A})$. Baseline $F E V_{1}$ represented by dashed horizontal line (study

Double blind sulfite dose-response challenges

No significant difference was observed in the lung function parameters of the four subjects after challenge with low and moderate sulfitecontaining wines compared with sulfite free wine (table 2). However, a significant difference was observed in their responsiveness to high sulfite wine compared with sulfite free wine. Individual lung function data clearly showed that all four subjects challenged with high sulfite wine experienced a fall in $\mathrm{FEV}_{1}$ of $>15 \%$ which was considered indicative of a positive response to challenge (fig 1). All these responses were accompanied by a perception of worsening asthma symptoms (fig 2). The time course of these reactions indicated that they were maximal immediately following the consumption of wine (fig 3), with the maximum fall in $\mathrm{FEV}_{1}$ ranging from $15.1 \%$ (subject 18) to $45.7 \%$ (subject 4 ). In subjects 12 and 18 lung function recovered rapidly to baseline values within 15 minutes. Subject 4 exhibited a severe response in which $\mathrm{FEV}_{1}$ fell by $45.7 \%$ and required 60 minutes to recover to baseline levels. Subject 2, whose lung function fell by

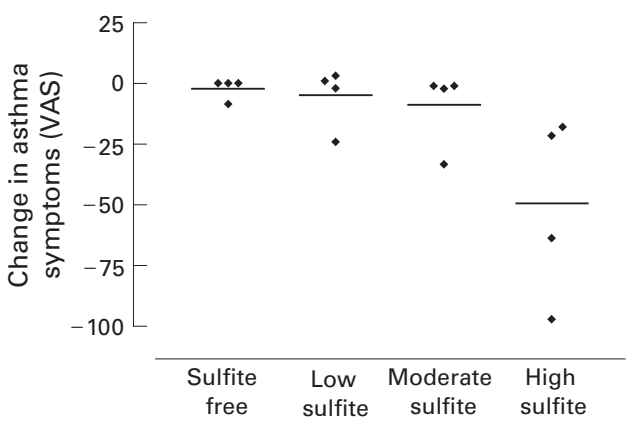

Figure 2 Subjective changes in asthma symptoms following challenge with wines containing varying sulfite concentrations as assessed by visual analogue scale (VAS). Negative changes reflect worsening asthma symptoms (study 1).

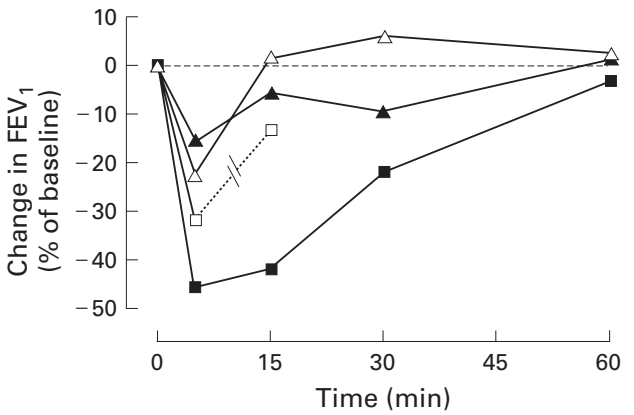

Figure 3 Time course of asthmatic responses to high sulfite (300 ppm) wine challenge in subjects 2 ( $\square), 4(\mathbf{\square}), 12$ $(\triangle)$, and $18(\mathbf{\Delta})$. Line break indicates that $\beta_{2}$ agonist treatment was administered. Baseline $F E V_{1}$ represented by dashed horizontal line (study 1).

$31.7 \%$ following challenge, required $\beta_{2}$ agonist therapy which subsequently resolved the asthma symptoms and dramatically improved lung function.

CUMUlative DOSE CHALlENGE STUdy (STUDY 2) Subjects

The characteristics of the control and wine sensitive asthmatic subjects recruited for this study are summarised in table 3. The control asthmatic group consisted of four women and two men of mean age of 26.7 (7.0) years. The wine sensitive group consisted of 12 women of mean age of 39.8 (10.5) years. Statistical analyses indicated that the normal asthmatic group was significantly younger than the wine sensitive group $(p=0.014)$ but there was no difference in baseline mean \% predicted $\mathrm{FEV}_{1}$ between the two groups.

\section{Cumulative dose challenges}

All patients recruited into this study were unresponsive to challenge with sulfite free wine. These patients were subsequently challenged with wines containing increasing levels of sulfite. Measurements of spirometric parameters $\left(\mathrm{FEV}_{1}, \mathrm{PEF}, \mathrm{FEF}_{25-75}\right)$ did not reveal any significant differences in sensitivity to the sulfite additives between self-reporting wine sensitive asthmatic subjects and controls ( $p$ values comparing the mean maximum fall of $\mathrm{FEV}_{1}, \mathrm{PEF}, \mathrm{FEF}_{25-75}$ for each of the groups studies: $\mathrm{p}=0.141, \mathrm{p}=0.240, \mathrm{p}=0.121$, respectively, fig 4).

Examination of individual data indicated that only two individuals from the wine sensitive group (subjects W1 and W10) exhibited a significant decline in lung function following cumulative challenge. Subject W1 had a fall in $\mathrm{FEV}_{1}$ of $22.9 \% 5$ minutes after challenge with $300 \mathrm{ppm}$ sulfite containing 


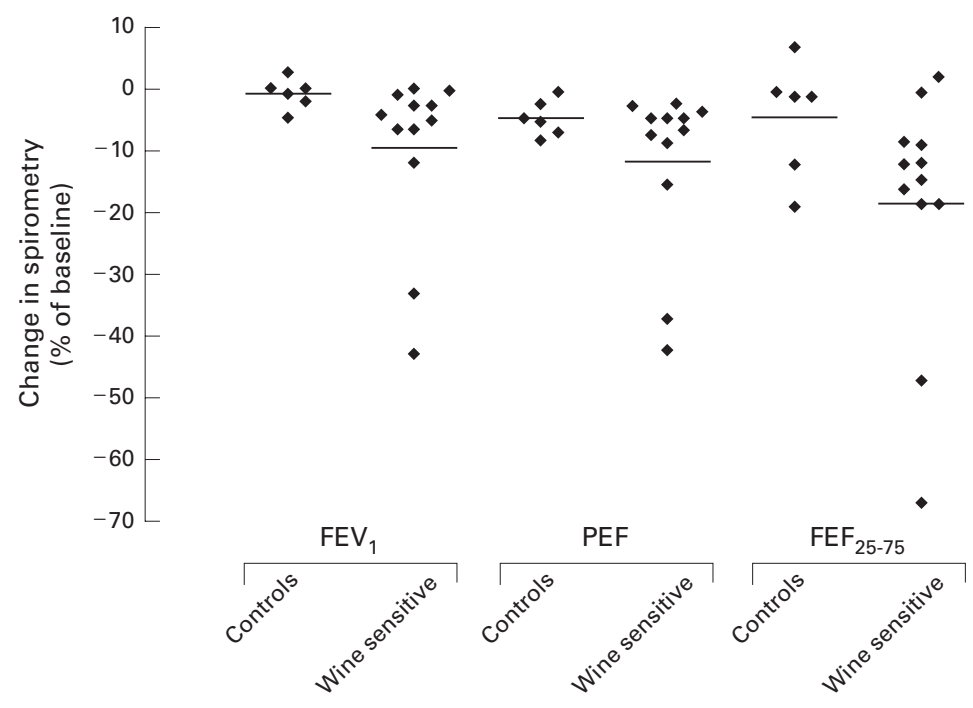

Figure 4 Maximum changes in FEV,$P E F$, and $F E F_{25}$ in control and wine sensitive asthmatic subjects following cumulative dose challenge. Mean maximum change for each parameter indicated by horizontal line (study 2).

wine, which improved to $12.1 \%$ below baseline by 15 minutes. The challenge of this same subject with $450 \mathrm{ppm}$ wine resulted in a dramatic decline in $\mathrm{FEV}_{1}$ by $42.6 \%$, which improved to $25.4 \%$ below baseline at 15 minutes. For safety reasons, challenge with wine containing $750 \mathrm{ppm}$ sulfite was not pursued. In contrast, subject W10 did not respond to challenge with the $150 \mathrm{ppm}, 300 \mathrm{ppm}$, or $450 \mathrm{ppm}$ sulfitecontaining wine, but exhibited a fall in $\mathrm{FEV}_{1}$ of $32.9 \%$ in response to challenge with wine containing $750 \mathrm{ppm}$ sulfite. In this subject, administration of $\beta_{2}$ agonists resulted in the rapid recovery of $\mathrm{FEV}_{1}$ to baseline levels. Three subjects (W1, W2 and W3) participating in the cumulative challenge study had previously had a positive response to a single dose high sulfite $(300 \mathrm{ppm})$ wine challenge (study 1). The maximum fall in $\mathrm{FEV}_{1}$ for all these individuals was greater after a single dose challenge than cumulative challenges.

\section{Discussion}

Following challenge with a single dose of high sulfite wine, only four of 23 self-reporting wine sensitive asthmatic subjects could be shown to be sensitive to the sulfite additives, despite the fact that sulfites have been suggested as being a major cause of wine induced asthma. Significantly, the four individuals who were shown to be sensitive to the sulfites in wine in this study only responded to wine containing $300 \mathrm{ppm}$ of this additive, which is the maximum level of sulfite allowable in Australian wines. ${ }^{7}$ There were no responses to wine containing 20$150 \mathrm{ppm}$ sulfite, although all four individuals provided histories suggesting that they were exquisitely sensitive to sulfite in wine and that most Australian wines have sulfite levels which are in the lower range of those used in this study. ${ }^{8}$

Although one explanation for this lack of responsiveness to challenge is that sensitivities to wine are largely psychologically mediated, this seems unlikely to explain fully the disparity between self-reported wine sensitive asthma and those responses that could be confirmed by challenge in this study. Asthmatic responses to wine are consistently reported as having a rapid time of onset and specifically inducing asthma symptoms. Individuals also reported repeated episodes of wine induced asthma over long periods of time, suggesting that responses to wine are real and that most of these responses are triggered by a single aetiological agent. Possibly of greater significance, however, was the overall lack of placebo responses in our studies, and the strong concordance observed between symptoms and $\mathrm{FEV}_{1}$ which further argued against wine induced asthma being a psychosomatic phenomenon in this cohort.

An alternative explanation for the lack of positive responses to challenge is that wine sensitive asthmatics are more sensitive to the sulfites in wine when consumed in natural settings than in the formal challenge environment

Table 3 Characteristics of control (C) and wine sensitive (W) asthmatic subjects (study 2)

\begin{tabular}{|c|c|c|c|c|c|c|c|}
\hline Patient no & Sex & Age (years) & $\begin{array}{l}\text { Skin prick } \\
\text { positive }\end{array}$ & $\begin{array}{l}\text { Asthma } \\
\text { medications }{ }^{1}\end{array}$ & $\begin{array}{l}\text { History of wine } \\
\text { sensitivity }^{2}\end{array}$ & $\begin{array}{l}\text { Baseline } \\
F_{E V} V_{1}(l)\end{array}$ & $\begin{array}{l}\text { Baseline } F E V_{1} \\
\text { (\% pred) }\end{array}$ \\
\hline C1 & $\mathrm{F}$ & 29 & $\mathrm{Y}$ & ba & NA & 3.07 & 95.0 \\
\hline $\mathrm{C} 2$ & $M$ & 36 & $\mathrm{Y}$ & ba & NA & 4.47 & 101.1 \\
\hline C3 & M & 33 & $\mathrm{Y}$ & $\mathrm{ba}, \mathrm{bc}$ & NA & 4.99 & 116.3 \\
\hline $\mathrm{C} 4$ & $\mathrm{~F}$ & 20 & $\mathrm{Y}$ & $\mathrm{ba}, \mathrm{bc}$ & NA & 2.99 & 100.3 \\
\hline C5 & $\mathrm{F}$ & 22 & $\mathrm{Y}$ & $\mathrm{ba}$ & NA & 2.39 & 84.8 \\
\hline C6 & $\mathrm{F}$ & 20 & $\mathrm{Y}$ & ba & NA & 1.84 & 54.6 \\
\hline $\mathrm{W} 1^{\star}$ & $\mathrm{F}$ & 32 & $\mathrm{Y}$ & ba & red, wh, champ & 3.18 & 104.6 \\
\hline $\mathrm{W} 2^{\star}$ & $\mathrm{F}$ & 25 & $\mathrm{Y}$ & ba & red, wh & 2.40 & 63.7 \\
\hline W3* & $\mathrm{F}$ & 27 & $\mathrm{Y}$ & $\mathrm{ba}, \mathrm{bc}$ & red, wh & 3.86 & 108.4 \\
\hline W4 & $\mathrm{F}$ & 51 & $\mathrm{Y}$ & ba, bu, sm & red, wh & 2.43 & 94.9 \\
\hline W5 & $\mathrm{F}$ & 32 & $\mathrm{Y}$ & ba & wh, champ & 2.86 & 86.1 \\
\hline W6 & $\mathrm{F}$ & 53 & $\mathrm{Y}$ & $\mathrm{ba}, \mathrm{bc}$ & red, wh & 2.48 & 85.2 \\
\hline W7 & $\mathrm{F}$ & 39 & $\mathrm{Y}$ & ba & red, wh, champ & 3.04 & 87.9 \\
\hline W8 & $\mathrm{F}$ & 56 & $\mathrm{Y}$ & ba & red, wh, champ & 2.56 & 103.2 \\
\hline W9 & $\mathrm{F}$ & 46 & $\mathrm{Y}$ & $\mathrm{ba}, \mathrm{fl}, \mathrm{sm}$ & wh & 1.99 & 71.8 \\
\hline $\mathrm{W} 10$ & $\mathrm{~F}$ & 37 & $\mathrm{Y}$ & ba, bu & red, wh & 1.91 & 71.3 \\
\hline W11 & $\mathrm{F}$ & 33 & $\mathrm{Y}$ & $\mathrm{ba}, \mathrm{bc}$ & wh & 2.23 & 73.1 \\
\hline W 12 & $\mathrm{~F}$ & 47 & $\mathrm{Y}$ & $\mathrm{ba}, \mathrm{bu}$ & red, wh & 1.81 & 77.0 \\
\hline
\end{tabular}

$\mathrm{FEV}_{1}=$ forced expiratory volume in one second; $\%$ pred $=$ percentage of predicted value.

${ }^{1} \mathrm{ba}=\beta_{2}$ adrenoceptor agonists; $\mathrm{bc}=$ beclomethasone; $\mathrm{bu}=$ budesonide; $\mathrm{fl}=$ flixotide $\mathrm{cr}=$ cromoglycate; $\mathrm{sm}=$ salmeterol; ip $=\mathrm{ipra}-$ tropium bromide; th $=$ theophylline.

${ }^{2} \mathrm{red}=$ red wine; wh $=$ white wine champ $=$ champagne ch $=$ cheap wine.

*Subjects responding to single dose high sulfite wine challenge in study 1 (subjects W1, W2 and W3 were subjects 4,18 and 2 , respectively, in study 1 ). 
of the laboratory. The reasons for this are not clear, but it may be that cofactors not present at the time of wine challenge may play an important role in these responses. We have previously reported anecdotal evidence suggesting that asthma stability may also play a role in the reactivity of asthmatic subjects to wine, with some reporting that their responses to wines are more noticeable in smoky environments or at certain times of the year when their asthma is generally less stable. ${ }^{3}$ Dahl et $a l^{4}$ also reported that some patients with pollen allergy have increased reactivity to red wines in the pollen season but not during the rest of the year, further indicating the role of cofactors in wine induced asthma. Thus, in the clinical laboratory setting and with preset criteria for asthma stability, the threshold of tolerance to sulfites may be increased.

Despite the possible complex nature of wine induced asthma, this study provided an opportunity to document the characteristics of asthmatic responses to sulfites in wine in those subjects who were exquisitely sensitive to these additives. Responses to high sulfite wine were very rapid, with the maximal fall in $\mathrm{FEV}_{1}$ in all subjects occurring 5 minutes after the challenge. This rapid response is consistent with the information obtained from most wine sensitive individuals in our previous questionnaire based study characterising these reactions, ${ }^{1}$ and is also consistent with asthmatic reactions to sulfited solutions described in other studies. ${ }^{9}{ }^{10}$ Following challenge with high sulfite wine, lung function returned to baseline levels 15-60 minutes after the challenge in positive responders in the absence of rescue therapy and, where treatment was supplied, $\beta_{2}$ agonist therapy proved to be rapidly effective in improving lung function and symptoms.

The rapid onset of asthmatic responses to sulfites in wine supports a local airway mechanism of action for these additives and the likely involvement of neural mechanisms in these responses. It is generally believed that cholinergic pathways play an important role in sulfite induced asthma. However, the variable efficacy of anticholinergic agents in protecting against sulfite induced bronchoconstriction ${ }^{11-13}$ suggests that other pathways may be involved, particularly when these responses are severe. ${ }^{14}$ The non-adrenergic non-cholinergic arm of the nervous system may be involved in these responses, ${ }^{15}$ with evidence for the involvement of tachykinins ${ }^{16}$ and bradykinin. ${ }^{17}$ However, prostaglandins $^{18}{ }^{19}$ and leukotrienes ${ }^{20}$ may also be involved in sulfite induced asthma. Clearly, the mechanisms underlying sulfite additive induced asthma are poorly understood, and mechanistic studies using models reflecting exposure to these additives as they occur in foods and drinks are required.

Because of the possibility that the study subjects had a decreased sensitivity to the sulfite additives in wine in our clinical challenges, we adopted a cumulative challenge protocol which, it was envisaged, would detect more subtle differences in the sensitivities of asthmatic subjects to sulfites in wine. Asthmatic subjects were exposed to increasing concentrations of sulfite additives in a single sitting. Furthermore, the concentrations of sulfite in two of the wines was increased beyond the levels normally present to help overcome any possible inhibitory effect associated with the controlled nature of the challenge environment. No significant difference was observed in sensitivity to the sulfite additives between wine sensitive and control asthmatic subjects, but this may have been due to limitations in the power of the study. Importantly, our results showed that the cumulative dose protocol was actually a less sensitive indicator than the single dose challenge for detecting sensitivity to sulfites in wine. This was evident in three individuals who had previous positive responses to single dose high sulfite wine challenges in study 1 (subjects W1, W2 and W3) but who exhibited less intense responses to cumulative challenge, despite the higher concentrations of sulfite in this latter protocol. One possible reason for the lack of sensitivity of asthmatic subjects to the cumulative challenge protocol is that tachyphylaxis to sulfite was induced during the challenge protocol; however, studies addressing this issue have produced conflicting results. ${ }^{21-23}$

In conclusion, our studies have shown that single dose challenges with sulfited wine appear to be of limited value in detecting sensitivity to wine. The controlled nature of the challenge environment, combined with the strict entry criteria regarding asthma severity and stability, may have reduced the sensitivity of the subjects to sulfites in wine. We therefore attempted to increase the sensitivity of our challenge tests by using a sulfited wine cumulative dose protocol in which subjects were challenged with increasing doses of sulfite in sequential fashion. However, the hypothesis that cumulative dose challenge would compensate for the controlled nature of the challenge environment and reveal sulfite sensitivities not detected by single dose challenge was not substantiated. Further refinement of existing challenge protocols and/or the development of new strategies may be needed to test the hypothesis that there is an increased sensitivity to sulfite additives in wine induced asthmatics, and to show that wine induced asthma is a significant problem in the community.

The authors would like to thank BRL Hardys for their generous donation of the preservative free wines used in this study and the Asthma Foundation of Western Australia for their support of this work

1 Vally $\mathrm{H}$, de Klerk $\mathrm{N}$, Thompson PJ. Alcoholic drinks: important triggers for asthma. $\mathcal{F}$ Allergy Clin Immunol 2000;105:462-7.

2 Gershwin M, Ough C, Bock A, et al. Grand rounds: adverse reactions to wine. $\mathcal{F}$ Allergy Clin Immunol 1985;75:411-20.

3 Vally H, Carr A, El-Saleh J, et al. Wine-induced asthma: a placebo controlled assessment of its pathogenesis. $\mathcal{F}$ Allergy Clin Immunol 1999;103:41-6.

4 Dahl R, Henriksen J, Harving H. Red wine asthma: a controlled challenge study. F Allergy Clin Immunol 1986;78: 1126-9.

5 Halpern GM, Gershwin E, Ough C, et al. The effect of white wine upon pulmonary function of asthmatic subjects. Ann Allergy 1985;55:686-90.

6 Rankine B. New method for determining sulfur dioxide in wine. Aust Wine Brew E Spirit Rev 1962;80:14-6.

7 Western Australian Food Monitoring Program. Sulfur dioxide in foods. Chemistry Centre (WA), Department of Mines \& Health Department of Western Australia, 1992. 
8 Wall PJ, Stockley CS. The usage of sulfur dioxide in Australian winemaking. Australian Wine Research Institute, 1998.

9 Delohery J, Simmul R, Castle WD, et al. The relationship of inhaled sulfur dioxide reactivity to ingested sensitivity in patients with asthma. Am Rev Respir Dis 1984; 130:1027-32

10 Baker GJ, Allen DH. The spectrum of metabisulphite induced asthmatic reactions; their diagnosis and management. Aust NZ F Med 1982;12:213.

11 Dixon C, Ind P. Metabisulfite-induced bronchconstriction: mechanisms. Am Rev Respir Dis 1988;137:238.

12 Seale P, Temple DM, Tennant CM. Bronchoconstriction by nebulized metabisulfite solutions $\left(\mathrm{SO}_{2}\right)$ and its modification by ipratropium bromide. Ann Allergy 1988;61:209-13.

13 Nichol G, Nix A, Chung K, et al. Characterization of bronchoconstrictor responses to sodium metabisulfite aerosol in atopic subjects with and without asthma. Thorax 1989;44: atopic subicis

14 Nichol GM, Alton EW, Nix A, et al. Effect of inhaled furosemide on metabisulfite- and methacholine-induced bronchoconstriction and nasal potential difference in asthbronchoconstriction and nasal potential difference in

15 Sun J, Sakamoto T, Chung KF. Effects of sodium Sun J, Sakamoto T, Chung KF. Effects of sodium metabisulphite on guinea pig contractile airway

16 Sakamoto T, Tsukagoshi H, Barnes P, et al. Involvement of tachykinin receptors (NK1 and NK2) in sodium metabisulfite-induced airway effects. Am F Respir Crit Care Med 1994;149:387-91.
17 Mansour E, Ahmed A, Cortes A, et al. Mechanisms of metabisulfite-induced bronchoconstriction: evidence for bradykinin $\beta_{2}$-receptor stimulation. F Appl Physiol 1992;72: 1831-7.

18 O'Connor B, Barnes PJ, Chung KF. Inhibition of sodium metabisulfite induced bronchoconstriction by frusemide in asthma: role of cyclooxygenase products. Thorax 1994;49: 307-11.

19 Wang M, Wisniewski A, Pavord I, et al. Comparison of three inhaled non-steroidal anti-inflammatory drugs on the airway response to sodium metabisulfite and adenosine 5'-monophosphate challenge in asthma. Thorax 1996;51: 799-804.

20 Lazarus SC, Wong HH, Watts MJ, et al. The leukotriene receptor antagonist zafirlukast inhibits sulfur dioxideinduced bronchoconstriction in patients with asthma. Am $\mathcal{F}$ Respir Crit Care Med 1997;156:1725-30.

21 Pavord ID, Wisniewski A, Tattersfield AE. Refractoriness to inhaled sodium metabisulfite in subjects with mild asthma. Eur Respir f 1994;7:50-4.

22 Nichol GM, Nix A, Chung KF, et al. Characterisation of bronchoconstrictor responses to sodium metabisulfite aerosol in atopic subjects with and without asthma. Thorax 1989;44:1009-14.

23 Wright W, Zhang YG, Salome CM, et al. Effect of inhaled preservatives on asthmatic subjects. I. Sodium metabisulfite. Am Rev Respir Dis 1990;141:1400-4. 